\title{
Evolving the diagnostic criteria for multiple sclerosis
}

Multiple Sclerosis - MS. These two letters change lives in an instant. Young people starting out in their careers and families. MS is hard to define, hard to treat, and hard to take. Yet over the past two decades, treatment has changed radically, from none, to over a dozen disease modifying compounds, that are able to reduce attack rate and mitigate disability. In 2017, this new revision of the MS diagnostic criteria, ${ }^{1}$ is an opportunity for reflection.

McAlpine's Multiple Sclerosis ( $4^{\text {th }}$ edition) provides a detailed coverage of the condition and the genesis of the classification. ${ }^{2}$ As so often in neurology, the lineage can be traced directly to JeanMartin Charcot, who shaped the term disseminated sclerosis. These words contain the essence of the disease, dispersed in the central nervous system, in time and in neuroanatomical space.

The criteria have themselves moved on through time, so that in the past 65 years there have been Allison and Millar (1954), Schumacher (1965), Poser (1983), and McDonald (2001, 2005, and 2010). At the core is a diagnostic process, carried out by an experienced neurologist, on an inflammatory demyelinating substrate, where phenocopies have been eliminated, along the axes of time and space. In Poser clinically definite MS, two or more attacks and two or more anatomical sites were required, though there was room for proxy laboratory support (such as electrophysiology and CSF markers) in the lower order categories. The advent of MRI has been central to the four later iterations (McDonald 2001-2017), with exact specifications for lesion number, gadolinium enhancement, and site, although the need for objective clinical evidence remains. In the 2017 McDonald criteria, the revival of CSF is particularly noteworthy.

What effect did these evolutions have? One clear result was a reduction in the diagnostic time, from 2 years (Poser) to 6 months (2010 McDonald criteria). ${ }^{3}$ This in turn, has intensified the desired therapeutic goal of treating the pathological process earlier towards the origin of the disease.

Jeremy Chataway

References

1) Thompson AJ, Banwell BL, Barkhof $F$, et al. Diagnosis of multiple sclerosis: 2017 revisions of the McDonald criteria. Lancet Neurol 2017;17: 162-73.

2) Compston A, McDonald I, Noseworthy J, et al. McAlpine's Multiple Sclerosis, 4th edn. Philadelphia: Churchill Livingstone, 2006.

3) Brownlee WJ, Swanton JK, Altmann DR, Ciccarelli O, Miller DH. Earlier and more frequent diagnosis of multiple sclerosis using the McDonald criteria. J Neurol Neurosurg Psychiatry 2015;

86: 584-85. 